\title{
Social emergency medicine: A way forward for training
}

\author{
Vivian Tam (1), MD*; Elisha Targonsky, $\mathrm{MD}^{\dagger}$ \\ INTRODUCTION
}

One of the most memorable patient encounters I have had took place late one night in the emergency department. As I went to grab the next chart off the rack, I noticed something: the normally long sticker detailing patient demographics was unusually short. In fact, for this patient, beside each field, "next of kin," "home address," "family physician," and "emergency contact," there was listed a variation of the same word: "none."

The patient turned out to be Rajiv (name and identifying details changed for privacy), a 36-year-old transiently housed man who had been assaulted while panhandling outside of a bar. I found him sitting in a bay with the lights out. Gauze was wrapped around his head, darkened by the blood of a superficial forehead laceration where he had hit the ground. His CT head came back unremarkable, "no breaks or bleeds," I told him, and after performing a brief neurological screen, my preceptor and I sent him back out into the night. No social worker overnight, I had heard earlier, and Rajiv did not want to stay until the morning.

My encounter with Rajiv stayed with me because of what I had not done as opposed to what I did. I had not, for instance, asked where he might be going back to or whether he would be safe there. I had not inquired as to whether he would have enough to eat, or whether he had somewhere to go in case the weather turned. And while I had ruled out potentially dangerous medical conditions, I had not thought to ask about the conditions that would shape far more of his life than his short brush with the health care system. Our interaction left me wondering: how could I have done more?

\section{SOCIAL DETERMINANTS IN THE EMERGENCCY DEPARTMENT}

Emergency rooms have long been considered society's "safety net," where patients have turned when they are most physically, mentally, or socially unwell. While all clinicians are trained in current approaches to medical diagnoses, challenging social conditions are often neglected, or seen as falling largely under the purview of our allied health staff. But as the most responsible provider, the physician is ultimately tasked with disposition planning. As well, a large retrospective Canadian study found that allied health professionals were not available the majority of the time $(52.7 \%$ of cases) that highfrequency users tended to visit the emergency department (during the evening and overnight). ${ }^{1}$

Some staff physicians' and residents' reticence toward treating individuals with conditions such as homelessness ${ }^{2}$ may stem from looking at social circumstances as non-life-threatening. However, across the United States, the number of deaths attributable to low education and social support were even higher than those attributed to acute myocardial infarction and cerebrovascular accident, respectively. ${ }^{3}$

Mortality notwithstanding, deep-rooted social conditions, such as homelessness, are responsible for some of the most pervasive issues confronting emergency departments today. Homeless individuals visit the emergency department 9 to 13 times more often than their agematched, securely housed peers; are much more likely to be admitted to hospital; and have significantly costlier hospital admissions, even after adjusting for length of stay. ${ }^{4,5}$

In light of these data, it becomes difficult to argue that social conditions can be seen solely as frustrating

From the *Department of Family and Community Medicine, Mount Sinai Hospital, University of Toronto, Toronto, ON; and the ${ }^{\dagger}$ Department of Emergency Medicine, North York General Hospital, University of Toronto, Toronto, ON.

Correspondence to: Dr. Vivian Tam, Department of Family and Community Medicine, University of Toronto, Mount Sinai Academic Family Health Team, 60 Murray Street, 4th Floor, Toronto, ON M5T 3L9; Email: vivian.tam2@sinaihealthsystem.ca

(C) Canadian Association of Emergency Physicians 2020

CJEM 2020;22(4):450-453

DOI 10.1017/cem.2020.8 
individual characteristics, as opposed to systemic issues that emergency clinicians can, and, if we are to make headway on issues such as frequent return visits, should play a role in addressing.

\section{THE EMERGENCE OF SOCIAL EMERGENCY MEDICINE}

One way to address the social inequities underlying many emergency department presentations is to incorporate principles of "social emergency medicine" in practice (Table 1).

Social emergency medicine incorporates knowledge of the individual's social context into their care in the emergency department. It takes a systematic approach to the patient's life context: screening, diagnosing, and treating social factors, such as homelessness, the same way a practitioner would approach chest pain. ${ }^{6}$
This emerging approach is essential to providing adequate person-centered care. Factors such as financial strain or housing security greatly alter how feasible, safe, or effective any given treatment and discharge plan will be. Had I considered Rajiv's housing status, for instance, I may have helped him locate a shelter with available space, or suggested more strongly he speak with our social worker. At the least, I might have ensured he had a taxi voucher with which to mitigate the cost of travel to wherever he was staying. Instead, I did not ask, and he returned to the same circumstances in which he had been assaulted, injured, and no better equipped to secure his personal safety.

In addition to being the morally sound and patientcentered approach to care, there is a fiscal argument for social emergency medicine as well. When implemented in full, a social emergency medicine approach will result in substantive cost savings for the health system. For

\begin{tabular}{|c|c|}
\hline Target population & Strategy to incorporate social emergency medicine principles \\
\hline \multirow[t]{5}{*}{ Clinician } & Screen for the social determinants using validated tools or institution-developed questionnaires \\
\hline & $\begin{array}{l}\text { Ask about the individual's social context and consider how this impacts their presentation. For instance, a child } \\
\text { presenting with recurrent asthma exacerbations as a result of living in an environment polluted by secondhand } \\
\text { smoke or mold }\end{array}$ \\
\hline & $\begin{array}{l}\text { Learn about existing local resources and their referral pathways, be vigilant in identifying ways to advocate for the } \\
\text { patient, including securing language interpretation, writing sick notes, employer or landlord letters, and ensuring } \\
\text { appropriate referrals are completed }\end{array}$ \\
\hline & Use supervisory positions to role model and teach social emergency medicine concepts to medical learners \\
\hline & $\begin{array}{l}\text { Join professional associations offering formal sections on social emergency medicine for continuing professional } \\
\text { development, learning, engagement, and networking in the field, including those offered by the Emergency } \\
\text { Medicine Residents' Association and the American College of Emergency Physicians }\end{array}$ \\
\hline \multirow[t]{3}{*}{ Educator } & $\begin{array}{l}\text { In medical school: Design cases with the patient's social context in mind; i.e., a patient with poor diabetes control } \\
\text { as a result of a lack of access to medications, caregiver responsibilities precluding intentional exercise, high cost } \\
\text { of nutritional food }\end{array}$ \\
\hline & $\begin{array}{l}\text { In residency training: Include 'social medicine' as an Entrustable Professional Activity as part of Competency by } \\
\text { Design when implementing curricular change, such that considering and treating patients in their social contexts } \\
\text { are denoted a competency on par with the management of physical disease }\end{array}$ \\
\hline & $\begin{array}{l}\text { Develop specialized training streams, including longitudinal immersive social emergency medicine experiences or } \\
\text { dedicated fellowships, which will enable residents to receive additional training, as well as research and create } \\
\text { interventions targeting health inequities commonly seen in the emergency department }\end{array}$ \\
\hline \multirow[t]{3}{*}{$\begin{array}{c}\text { Researcher and } \\
\text { policy-maker }\end{array}$} & $\begin{array}{l}\text { Undertake research to understand how a social emergency medicine approach can improve patient outcomes, } \\
\text { including morbidity and mortality, and its impact on alternate endpoints such as frequent return visits, } \\
\text { satisfaction with care, or personal well-being }\end{array}$ \\
\hline & $\begin{array}{l}\text { Leverage research findings to support and advocate for public policies that protect and enhance patients' health } \\
\text { and well-being, such as by writing editorials, engaging directly with policy-makers or organizations focused on } \\
\text { health equity }\end{array}$ \\
\hline & $\begin{array}{l}\text { Collaborate with colleagues to develop advocacy initiatives such as petitions or department-wide quality } \\
\text { improvement and research projects to address pressing health inequities faced by patients }\end{array}$ \\
\hline
\end{tabular}


instance, in one retrospective Canadian study, Hwang and Henderson found that $77.3 \%$ of the homeless population had presented to an emergency department over 1 year, with an annual rate of 2.1 visits and a cost of $\$ 1,464$ per person. ${ }^{7}$ The comparator population incurred only $13 \%$ of the total cost of the homeless population's emergency department visits over the same period. ${ }^{7}$ By reducing the volume of emergency department visits alone, social emergency medicine has the potential to significantly reduce expenditure within the public healthcare system.

Realizing the ethos of social emergency medicine will require a cultural shift from bedside care in the emergency department through to the level of the health system. The emergency practitioner cannot be expected to manage chronic issues beyond their encounter with the patient. However, as with any other medical condition, they bear the responsibility for providing a degree of care coordination and navigation for their patient. The same should apply when the upstream cause of the patient's illness is social.

In medical education, this shift should begin with ensuring future emergency physicians are: (1) familiar with potential referral pathways for addressing common social issues, (2) exposed to the potential for individualand system-level advocacy to improve the conditions shaping their patients' experiences of illness, and (3) proficient in the evidence supporting a social medicine approach. A successful model in the Cambridge Health Alliance's (CHA) social internal medicine curriculum can be used as the basis for designing the emergency medicine resident's experience. The CHA is a Harvard Medical School-affiliated training program, and, in 2012, it instituted a mandatory 1-year, longitudinal curriculum focused on health disparities and research-based health advocacy. Residents received didactic instruction on health equity, policy, and the social determinants of health; took field trips to visit advocacy organizations and policy-makers; and participated in research and advocacy workshops. The experience culminated in a group-based health advocacy research project. Over 4 years, residents responding to a programmatic survey (17 of 32 residents, or $53 \%$ ) rated the overall quality of the course a mean score of 5.2/6, where 6 was considered "outstanding". Qualitative responses suggested that residents thought the course was a rich and integral part of their residency experience. ${ }^{8}$ It is likely that Canadian emergency medicine residents would similarly benefit from structured exposure to a social and advocacy-based experience in their training.

\section{IN THE CANADIAN CONTEXT}

The authors of this study conducted an internet search and informal email poll of emergency medicine residency program administrators in August 2019 (Tam V. Personal communication, August 7-15, 2019.). We received six responses from the 14 English language programs contacted, which suggested that no formalized social emergency training programs currently exist in Canada. However, across numerous programs, there are extra-curricular opportunities for residents to engage in training that is consistent with the principles of social emergency medicine. For instance, the University of Toronto houses the Global Health Emergency Medicine (GHEM) Program, a group of clinicians and researchers that aims to produce academic outputs to inform health policy development and improve health equity in local and global contexts. ${ }^{9}$ Clinically relevant training opportunities also exist at numerous institutions in specialized areas, including the care of patients struggling with addictions and substance use, mental health concerns, and newcomer, immigrant, and refugee status.

\section{CONCLUSION}

The emergency department plays a vital role in serving the needs of sick patients. The emergence of social emergency medicine offers an opportunity for future providers to fulfill and expand that role to include consideration of the patient's social circumstances in determining their optimal treatment and discharge plan. The lack of formal, comprehensive social emergency medicine training streams in Canada represents an opportunity to reflect on this area of patient need, and our academic emergency medicine institutions are beginning to integrate principles of this new field into their program offerings. More widespread development of training streams, or the incorporation of a social emergency medicine approach to teaching within institutions will enable the upcoming generation of emergency providers to serve and advocate for both their patients and communities in a meaningfully holistic way.

Keywords: Education, emergency medicine, residents, fellows

Competing interest: None declared. 


\section{REFERENCES}

1. Kim JJ, Kwok ESH, Cook OG, Calder LA. Characterizing high frequency users of a large Canadian urban emergency department. West 7 Emerg Med 2018;19(6):926-33.

2. Fine AG, Zhang $T$, Hwang SW. Attitudes towards homeless people among emergency department teachers and learners: a cross-sectional study of medical students and emergency physicians. BMC Med Educ 2013; 13:112.

3. Galea S, Tracy M, Hoggatt KJ, DiMaggio C, Karpati A. Estimated deaths attributable to social factors in the United States. Am $\mathcal{F}$ Public Health 2011;101(8):1456-65.

4. Chambers C, Chiu S, Katic M, et al. High utilizers of emergency health services in a population-based cohort of homeless adults. Am 7 Public Health 2013;103: 302-10.
5. Gaetz S. The Real Cost of Homelessness: Can We Save Money by Doing the Right Thing? Toronto: Canadian Homelessness Research Network Press; 2012.

6. Hsieh D. Achieving the quadruple aim: treating patients as people by screening for and addressing the social determinants of health. Ann Emerg Health 2019;74(5):S19-24.

7. Hwang SW, Henderson MJ. Health Care Utilization in Homeless People: Translating Research into Policy and Practice. Rockville, MD: Agency for Healthcare Research and Quality, Working Paper No. 10002; 2010.

8. Basu G, Pels RJ, Stark RL, Jain P, Bor DH, McCormick D. Training internal medicine residents in social medicine and research-based health advocacy. Acad Med 2017;92(4):515-20.

9. Global Health Emergency Medicine (GHEM). About us. Toronto, ON: GHEM: 2019. Available at: http://ghem.ca/ about-us/ (accessed February 3, 2020). 